\title{
A New Method to Estimate the Influence of Organics on the Solubility and Speciation of Radionuclides ("The Backdoor Approach")
}

\author{
By W. Hummel \\ Paul Scherrer Institute, CH-5232 Villigen PSI, Switzerland
}

(Received October 25, 1991 ; revised January 20, 1992)

Organics / Model ligand / Radionuclides /

Complexation / Stability constants

\begin{abstract}
A new modelling approach for assessing the influence of organics in safety studies for radioactive waste repositories is described, beginning with the question, "What properties must an organic ligand have in order to significantly influence the speciation, and hence the solubility, of a given radionuclide?". An organic model ligand is used in this so called "backdoor" approach; the stability of the corresponding radionuclide - organic complex is a free variable and the stabilities of all organic complexes formed with competing cations in solution are considered as dependent on this one free variable. These dependencies are determined by methods based on correlations between measured stability constants of a large number of organic complexes with different cations. Example speciation calculations with the organic model ligand for two different water compositions and a given radioelement, $\mathrm{Ni}$, reveal three different possibilities as to the significance or organics, depending on the concentration of the organic ligand and the stability of complexes formed with the radioelement: Besides the two concentration - stability regions where no influence or significant influence of organics is expected, a third region exists where the stability of organic complexes with the competing cations determines the influence of the organic ligand on the speciation of the radionuclide.
\end{abstract}

\section{Introduction}

The importance of organics in safety assessment studies of radioactive waste repositories is an unresolved topic [1]. In many cases, geochemical calculations show poor agreement between predicted and observed radionuclide solubilities in the presence of dissolved organic material [2]. Due to the paucity of experimental data, especially in the cases of natural organics and organic degradation products in the nearfield, no significant improvement to speciation calculations has been achieved during the last decade. Traditional modelling approaches to this problem start with the selection of a specific organic ligand such as oxalate, citrate, EDTA etc., or any mixture of them, and thus at best only answer the questions concerning the selected ligand or mixture of ligands. This procedure of guessing which organic ligand(s) may be important obviously is a never ending story considering the large number of possible ligands.

In this paper a new modelling approach to the problem of organics is described which begins with the question, "What properties must an organic ligand have in order to significantly influence the speciation, and hence the solubility, of a given radionuclide?" The main properties considered in this so called "backdoor approach" are the concentration of the organic ligand in solution and the stability of the organic complex with a given radionuclide. In contrast to the traditional modelling approaches, the "backdoor" method works with an organic model ligand whose complex stability with the radionuclide is treated as a free variable. In addition, the stabilities of all complexes formed with competing cations in the solution must be considered as independent parameters assigned to the organic model ligand. In the following sections, first these parameters are discussed and it is shown how their number is reduced by methods based on correlations between experimentally determined stability constants of organic complexes with different cations. In the last section, example results of the backdoor approach are presented in some detail.

\section{The parameter space of the backdoor approach}

The backdoor approach can be described as the exploration of a geochemical parameter space. Each parameter like the solubility of a radionuclide, concentration of a solute, or stability of a complex, which is treated as a free variable in the geochemical calculations forms a dimension of the multidimensional parameter space. In order to show the feasibility of the backdoor approach we first have to discuss the dimensionality of this parameter space. As can be seen in Fig. 1, solubility and speciation of a given radionuclide (RN) in the presence of a hypothetical organic ligand ("org") is influenced by the radionuclide-organic complexes formed in solution. The concentrations of RN - "org" complexes, however, depend on a number of parameters: The main parameters are chosen to be the concentration of the radionuclide, the concentration of the organic ligand and the stability of the RN - "org" complexes. Further we have to take into account competing cations and anions. This means that not only the radionuclide but also dissolved cations, such as $\mathrm{Na}^{+}, \mathrm{K}^{+}, \mathrm{Mg}^{2+}, \mathrm{Ca}^{2+}, \mathrm{Sr}^{2+}, \mathrm{Mn}^{2+}, \mathrm{Fe}^{2+}, \mathrm{Fe}^{3+}$ and $\mathrm{Al}^{3+}$, may form complexes with the organic ligand. On the other hand, the radionuclide may form complexes with dissolved anions (e.g. $\mathrm{OH}^{-}, \mathrm{CO}_{3}^{2-}, \mathrm{SO}_{4}^{2-}, \mathrm{PO}_{4}^{3-}$, $\mathrm{Cl}^{-}, \mathrm{F}^{-}$). As additional free parameters we have there- 


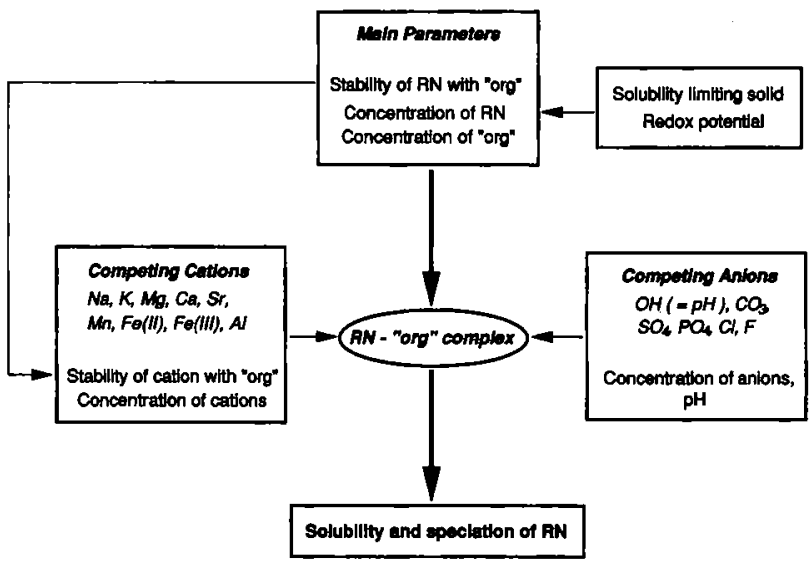

Fig. 1. Parameters influencing the solubility and speciation of a given radionuclide (RN) in presence of an organic model ligand ("org"). Arrows show the influence pattern.

fore to consider the concentrations of competing cations and anions and the stabilities of organic complexes formed with competing cations (Fig. 1). The stabilities of complexes of the radionuclide with competing anions are assumed to be sufficiently well known and need not to be treated as free variables. The simplest model of a hypothetical organic ligand assumes that only monomeric "org" complexes are formed. Thus, for each cation only a single stability parameter has to be considered. In the example given above (Fig. 1), including 10 cations and 6 anions, we have to work in a 26 dimensional parameter space (10 stability parameters and 16 concentration parameters). If the stability parameters are varied unconditionally in 5 steps and the concentrations in 3 steps, which is at the lower limit to fully explore the geochemical parameter space, about $5^{10} \cdot 3^{16} \simeq 4 \cdot 10^{14}$ speciation calculations have to be done for a single radionuclide. Thus, a "brute force approach", in which all these parameters are varied independently without any constraints, would require computing times in the range of geological time scale for each radionuclide: If a single geochemical calculation is finished in $1 \mathrm{sec}$, the calculations would take about 10 million years. The main task to make the "backdoor approach" a feasible tool is therefore a drastic reduction of the dimensionality of the parameter space of the geochemical model.

Let us first discuss the concentrations of the compounds. Geochemical equilibrium in solution requires an overall charge balance. The charge balance condition reduces the dimensionality of the parameter space by one, but still we have to carry out an impractical large number of computations. A drastic reduction of dimensionality can only be achieved considering hydrological arguments: The compositions of waters are not randomly distributed over the whole parameter space but usually cluster in certain domains. It is therefore sufficient to choose a small number of water compositions which represent the entire "populated" parameter space. If the radionuclide species in solution are in equilibrium with some solid phase or if a "typical" concentration is chosen, the sub-space of concentrations is reduced to a one-dimensional space: Only the concentration of the hypothetical organic ligand is left as a free variable, all the other concentrations are given by choosing a "water type" composition and a solubility limiting solid for the radionuclide.

The same argument as in the case of water compositions holds for the problem of complexes with the hypothetical organic ligand: The stabilities of organic complexes are not randomly distributed, but vary within certain ranges or even show a high degree of correlation. These ranges and correlations are discussed in some detail in the next section of this paper. As is shown below, the sub-space of stability parameters can be reduced to a one-dimensional space. Only the stability parameter of the radionuclide-organic complex remains as a free variable, all stabilities of organic complexes with the competing cations depend on this one free variable.

In conclusion, selecting a single "type" of water compositions and correlations of stability parameters we end up with a three-dimensional parameter space: The solubility of the radionuclide is a function of the two main parameters, concentration of the organic ligand and stability of the radionuclide - organic complex. To explore this three-dimensional parameter space requires 15-30 computations for each "type" of water composition. If some ten "water types" are selected to cover the whole range of water compositions, less than 400 computations for a specific radionuclide are needed.

\section{Correlations and ranges of stability constants}

The simplest model of a hypothetical organic ligand assumes that only monomeric complexes are formed:

$$
\mathrm{Me}+\text { org } \rightleftharpoons \text { Meorg }
$$

where $\mathrm{Me}$ is any metal cation and org is the organic ligand. Charges are not considered for simplicity. The mass action equation of this reaction is:

$$
K_{\text {Meorg }}=\frac{\{\text { Meorg }\}}{\{\mathrm{Me}\} \cdot\{\text { org }\}}
$$

where \{\} is the activity of a species and $K$ is the equilibrium quotient or stability constant, usually given in its logarithmic form $(\log K)$. If org is a hypothetical organic ligand as used in this modelling study, $K$ is a free variable and may be varied independently for every metal cation included in the geochemical model. As discussed above, this leads to an unfeasibly high number of computations. However there is a way out of this unfortunate situation if we use the information contained in the large variety of experimentally determined stability constants for a wide range of metal cations and organic ligands. The results of a century of work in analytical chemistry are ac- 


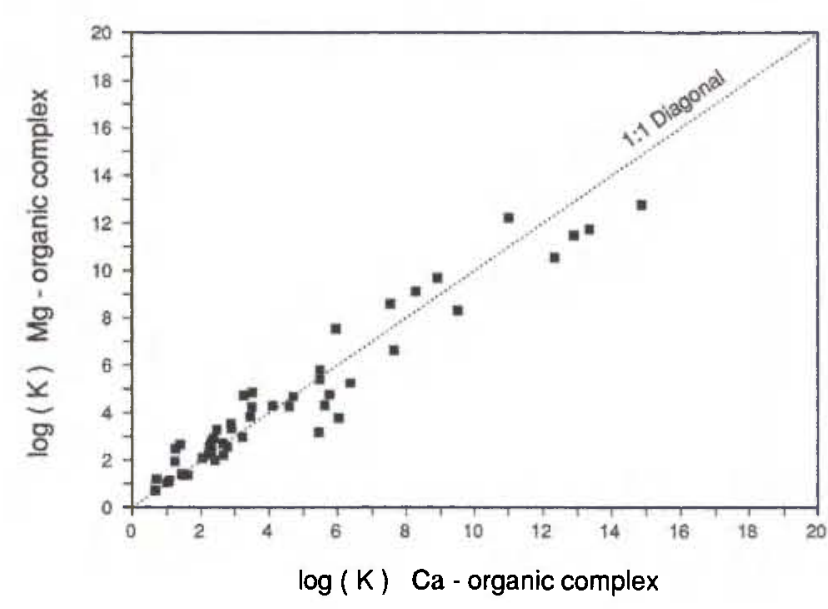

Fig. 2. Stability constants of monomeric organic complexes with calcium and magnesium. Data taken from Reference [3].

cumulated in critical reviews such as the volumes of the "Critical Stability Constants" by Smith and Martell [3]. From reference [3] a subset of stability constants $(\log K)$ was extracted in order to fill a data matrix of monomeric complexes defined by about 70 organic ligands and about 40 metal cations. Especially in the case of actinides experimental data are somewhat scarce and thus the data matrix contains a lot of "holes". Nevertheless, more than $1000 \log K$ values were found. The organic ligands were chosen according to the following criteria: First, the selected $\log K$ values should cover the whole range of experimentally determined stability constants. Second, the organic ligands should comprise the most common functional groups in any combination. The functional groups chosen are amino groups and oxo groups such as carboxylic acids, phenolic hydroxo groups and carbonylic groups. The metal cations divide into two groups: Cations found in common groundwaters such as $\mathrm{Ca}, \mathrm{Mg}, \mathrm{Fe}, \mathrm{Al}$ and radioelements such as $\mathrm{Ni}, \mathrm{Zr}$, $\mathrm{Th}, \mathrm{U}, \mathrm{Np}, \mathrm{Pu}, \mathrm{Am}$ including different redox states of $\mathrm{U}, \mathrm{Np}$ and $\mathrm{Pu}$. Inspecting this data matrix reveals that the $\log K$ values are not randomly distributed but show a high degree of correlation. If, for example, the $\log K$ values for all $\mathrm{Mg}$-organic complexes are plottéd against the values of all $\mathrm{Ca}-$ organic complexes, the data points cluster along the 1:1 diagonal within a range of about 15 orders of magnitude (Fig. 2). This means that the stability of the Mgorg complex, as a first approximation of the hypothetical organic ligand used in this modelling study, may be treated as a function of the stability of the Caorg complex: For any given value $\log K_{\text {Caorg }}$ the relation $\log K_{\mathrm{Mgorg}}=$ $(1.00+0.07) \cdot \log K_{\text {Caorg }}$ holds. This relation reduces the dimensionality of the parameter space by one and thus saves a lot of unnecessary calculations. By inspecting the other alkaline earth metal cations it is not surprising that linear relations of $\log K$ values are also found for $\mathrm{Ca}$ and $\mathrm{Sr}$ (Fig. 3) and for $\mathrm{Ca}$ and $\mathrm{Ba}$. In these cases the scatter of data points is even smaller than in the case of $\mathrm{Ca}$ and $\mathrm{Mg}$. The formally independent parameters of the Srorg and Baorg complex stab-

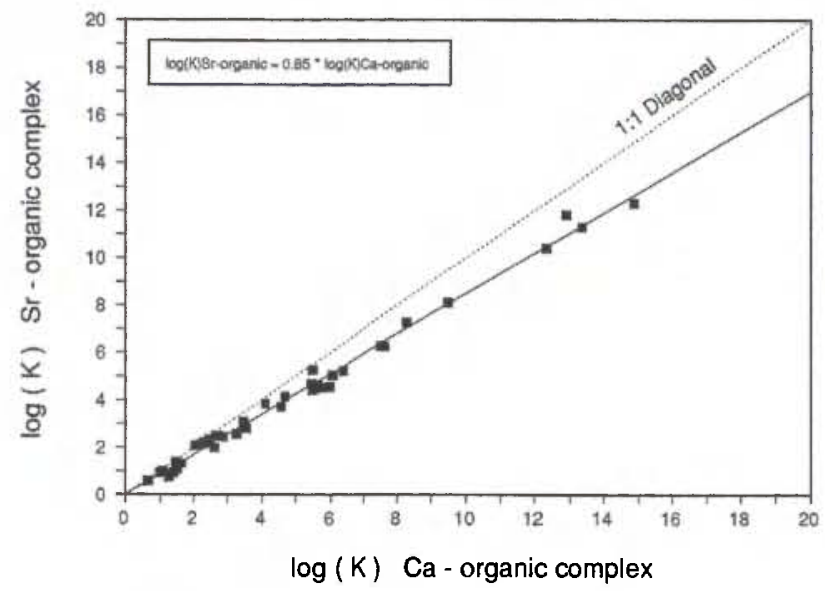

Fig. 3. Stability constants of monomeric organic complexes with calcium and strontium. Data taken from Reference [3].

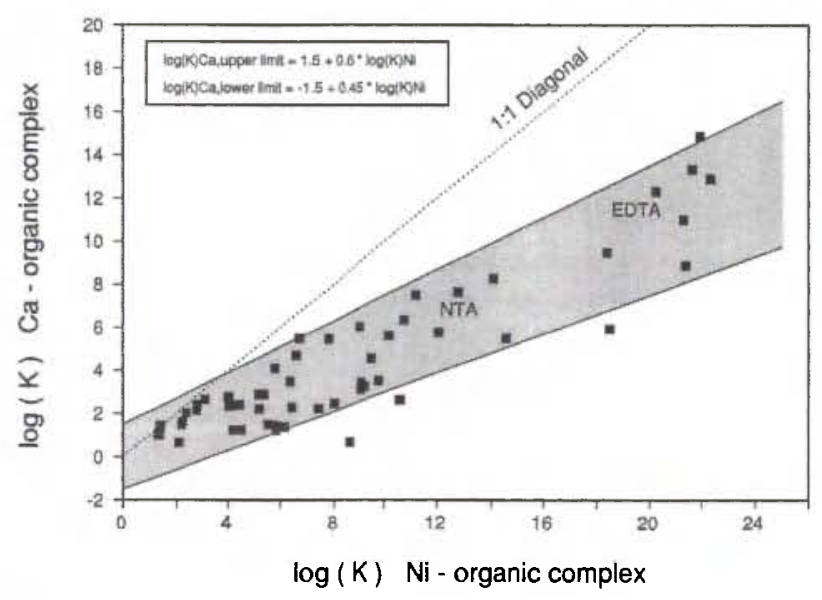

Fig. 4. Stability constants of monomeric organic complexes with nickel and calcium. Data taken from Reference [3]. NTA: nitrilotriacetic acid; EDTA: ethylenedinitrilotetraacetic acid.

ilities are replaced by the functions $\log K_{\text {Srorg }}=$ $(0.85+0.02) \cdot \log K_{\text {Caorg }}$ and $\log K_{\text {Baorg }}=(0.77+0.03)$ $\cdot \log K_{\text {Caorg. }}$. Similar linear relations are found for the $\mathrm{Na}-\mathrm{Ca}$ and $\mathrm{K}-\mathrm{Ca}$ distributions: $\log K_{\mathrm{Naorg}, \mathrm{Korg}}=$ $(0.23+0.06) \cdot \log K_{\text {Caorg }}$. (The standard errors of all coefficients are given as $2 \sigma$, representing the $95 \%$ confidence level.)

These findings are of course not new. Linear correlations of data are used in organic chemistry in a number of empirical models for the description of relationships between structure and reactivity. The most successful and intensively investigated are the linear free energy relationships (LFER), with the Hammett equation and the Taft equation as the most prominent examples [4]. But not all data show such strong linear correlations: In the case of $\mathrm{Ca}-$ and $\mathrm{Ni}$ - organic complexes the data scatter within a significant bandwidth (Fig. 4). Here a simple LFER approach would fail and therefore a different approach is necessary in order to reduce the dimensionality of the parameter space. If we take $\mathrm{Ni}$ as the radionuclide to be studied, the $\log K$ value of the Niorg complex is chosen as the free variable in the geochemical model. 


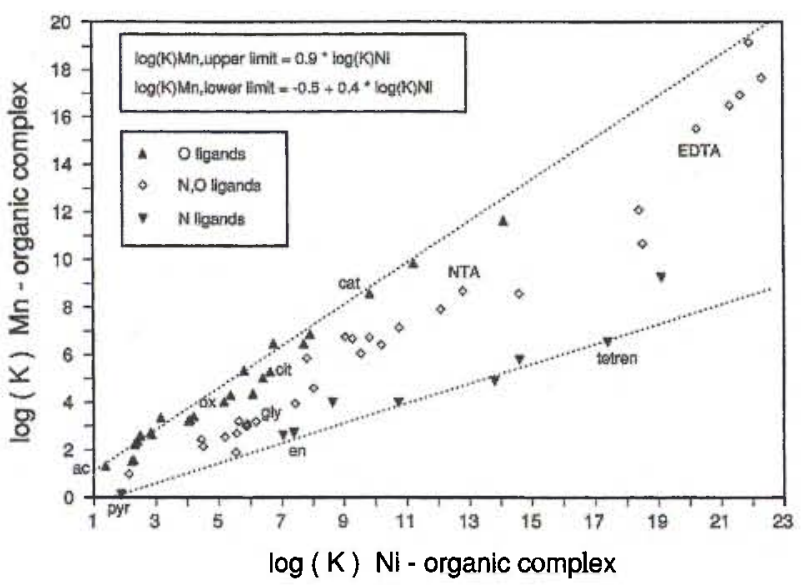

Fig. 5. Stability constants of monomeric organic complexes with nickel and manganese(II). Data taken from Reference [3]. ac: acetate; ox: oxalate; cit: citrate; cat: catecholate; gly: glycine; NTA: nitrilotriacetic acid; EDTA: ethylenedinitrilotetraacetic acid; pyr: pyridine; en: ethylenediamine; tetren: tetraethylenepentamine.

The corresponding stability constant of the Caorg complex is not a single value but varies within a certain range as is indicated by the grey area in Fig. 4. To cover the whole range of Caorg complex stabilities it is sufficient to do two speciation calculations for any given $\log K_{\text {Niorg }}$ using a lower limit and an upper limit of $\log K_{\text {Caorg }}$ values (Fig. 4). The lower limit corresponds to relatively weak Caorg complexes whereas the upper limit represents strong Caorg complexes. All other complexes fall somewhere in between these limiting values. But that is not all we can deduce from Fig. 4: Based on the correlations shown in Figs. 2 and 3, strong Caorg complexes correspond to strong Mgorg and Srorg complexes and weak Caorg complexes correlate with weak Mgorg and Srorg complexes. The same argument holds for $\mathrm{Ba}, \mathrm{Na}$ and $\mathrm{K}$. Thus, if we want to explore the parameter space of a simple system comprising the cations $\mathrm{Ni}, \mathrm{Ca}, \mathrm{Mg}$, $\mathrm{Sr}, \mathrm{Na}, \mathrm{K}$ and the $\log \mathrm{K}$ values of Niorg are varied, for example, in 5 steps we need $2 \cdot 5=10$ computations instead of $5^{6}=15625$ computations of the "brute force" approach.

The scatter of data shown in Fig. 4 is not caused by very unreliable data but has mainly chemical reasons. To illustrate this point, we take the distribution of $\mathrm{Mn}-$ and $\mathrm{Ni}$-organic complexes (Fig. 5) which shows even a larger scatter than the $\mathrm{Ca}-\mathrm{Ni}$ distribution. The organic ligands are discriminated into three types according to their functional groups: ligands containing only oxo-groups ("O-ligands"), ligands containing only amino - groups ("N-ligands") and ligands containing both groups ("N,O-ligands"). As can be seen in Fig. 5, all O-ligands form the upper limit of the distribution and show a strong linear correlation similar to the $\mathrm{Ca}-\mathrm{Mg}$ and $\mathrm{Ca}-\mathrm{Sr}$ distribution (Figs. 2 and 3). All N-ligands form the lower limit of the distribution and also show a strong linear correlation, whereas the mixed N,O-ligands fall in between the pure $\mathrm{N}$ - and $\mathrm{O}$-ligands. This distinct behavior of ligands with respect to different cations is of course not a new result, it merely illustrates with a large number of experimental data well known concepts such as Pearson's "hard" and "soft" acids or Schwarzenbach's class A, B and C cations [5]. Hard acids or class $\mathrm{A}$ cations such as $\mathrm{Ca}^{2+}, \mathrm{Mg}^{2+}$ or $\mathrm{Mn}^{2+}$ have low polarizability and tend to form largely electrostatic bonds with "hard" ligands such as O-ligands whereas complexes with $\mathrm{N}$-ligands are rather weak.

It is beyond the scope of this study to use the experimental stability data to develop a model of complex formation based on more fundamental considerations. A detailed review of such models and concepts is given by Langmuir [5]. A promising new approach, the "Unified Theory of Metal Ion Complex Formation", was developed by Brown and Sylva [6]. The aim of the theories and concepts described in [5] and [6] is mainly to estimate stability constants of specific aqueous complexes of geochemical interest where no experimental data are available. The goal of the purely empirical approach in this study is to explore the parameter space of all common organic ligands in order to define an organic model ligand where only the stability of the radionuclide-organic complex is a free variable and all the other cation-organic complexes depend on this free parameter. In contrast to methods based on LFER models, the success of the backdoor approach does not depend on strong correlations between stability parameters: If the data scatter within a significant bandwith, lower and upper limit functions are used in speciation calculations.

\section{Example results of the backdoor approach}

In order to show the feasibility and the main results of the backdoor approach, speciation calculations were done using an organic model ligand for given water chemistries and a given radionuclide. Two rather different "water type" compositions were chosen for the speciation calculations: a cement pore water which is an example of the nearfield water chemistry of a repository for low- and intermediate level radioactive wastes, and a marl-type groundwater as an example of the farfield water chemistry of a repository in sedimentary host rocks. Nickel is chosen as the radionuclide to be studied. This selection was made in view of to the amount and reliability of available experimental thermodynamic data. The stability constants of aqueous inorganic Ni complexes and the solubility data of $\mathrm{Ni}$ solids were taken from the critical data compilation of Baeyens and McKinley [7]. Using an organic model ligand in the speciation calculations, the stability of the $\mathrm{Ni}$-organic complex was treated as a free variable, whereas the stabilities of organic complexes formed with competing cations are given by linear functions of this one free variable. These linear functions are derived from a large body of experimental stability data as discussed in the previous sec- 
Table 1. Description of "water types"

\begin{tabular}{|c|c|c|}
\hline Parameter & $\begin{array}{c}\text { Cement pore water } \\
\text { Ref. [9] }\end{array}$ & $\begin{array}{c}\text { Marl groundwater } \\
\text { Ref. [10] }\end{array}$ \\
\hline $\begin{array}{l}\mathrm{Na}^{+}[\mathrm{M}] \\
\mathrm{K}^{+}[\mathrm{M}] \\
\mathrm{Mg}^{2+}[\mathrm{M}] \\
\mathrm{Ca}^{2+}[\mathrm{M}] \\
\mathrm{Sr}^{2+}[\mathrm{M}] \\
\mathrm{Cl}^{-}[\mathrm{M}] \\
\mathrm{F}^{-}[\mathrm{M}] \\
\mathrm{NO}_{3}^{-}[\mathrm{M}] \\
\mathrm{CO}_{3}^{2-}[\mathrm{M}] \\
\mathrm{SO}_{4}^{2-}[\mathrm{M}] \\
\mathrm{H}_{2} \mathrm{SiO}_{4}^{2-}[\mathrm{M}]\end{array}$ & $\begin{array}{l}1.219 \cdot 10^{-1} \\
4.700 \cdot 10^{-4} \\
1.130 \cdot 10^{-7} \\
2.140 \cdot 10^{-2} \\
9.200 \cdot 10^{-5} \\
7.616 \cdot 10^{-2} \\
1.359 \cdot 10^{-4} \\
1.610 \cdot 10^{-3} \\
1.150 \cdot 10^{-5} \\
1.551 \cdot 10^{-2} \\
1.260 \cdot 10^{-5}\end{array}$ & $\begin{array}{l}1.101 \cdot 10^{-1} \\
6.700 \cdot 10^{-4} \\
7.082 \cdot 10^{-4} \\
8.732 \cdot 10^{-4} \\
1.467 \cdot 10^{-4} \\
6.019 \cdot 10^{-2} \\
6.000 \cdot 10^{-4} \\
\\
3.105 \cdot 10^{-3} \\
2.514 \cdot 10^{-2} \\
2.791 \cdot 10^{-4}\end{array}$ \\
\hline $\begin{array}{l}\mathrm{pH} \\
\text { Ionic strength }\end{array}$ & $\begin{array}{c}12.59 \\
0.18\end{array}$ & $\begin{array}{l}8.18 \\
0.13\end{array}$ \\
\hline $\begin{array}{l}\text { Saturated solids } \\
(\mathrm{SI}=0)\end{array}$ & $\begin{array}{c}\text { Portlandite } \mathrm{Ca}(\mathrm{OH})_{2} \\
\text { Brucite } \mathrm{Mg}(\mathrm{OH})_{2} \\
\\
\text { Calcite } \mathrm{CaCO}_{3} \\
\mathrm{Gypsum} \\
\mathrm{CaSO}_{4} \cdot 2 \mathrm{H}_{2} \mathrm{O} \\
\text { Fluorite } \mathrm{CaF}_{2}\end{array}$ & $\begin{array}{c}\text { Calcite } \mathrm{CaCO}_{3} \\
\text { Dolomite } \\
\text { CaMg}\left(\mathrm{CO}_{3}\right)_{2} \\
\text { Strontianite } \mathrm{SrCO}_{3} \\
\text { Celestite } \mathrm{SrSO}_{4} \\
\\
\text { Fluorite } \mathrm{CaF}_{2} \\
\text { Chalcedony } \mathrm{SiO}_{2}\end{array}$ \\
\hline
\end{tabular}

tion. The present model does not include protonation equilibria. Their effects on the results of speciation calculations are highly ligand specific in the low $\mathrm{pH}$ range and they will have no effect at all in the case of the high $\mathrm{pH}$ cement pore water. The main reason for not considering protonation equilibria is that for the purpose of safety assessment studies, the present model represents the conservative (or worst) case, i.e. if there is any effect of protonation equilibria on the results it would be a decrease of the influence of organic ligands on the solubility and speciation of radionuclides. All speciation calculations were carried out using the geochemical modelling program MINEQL/ PSI [8].

\section{Cement pore water}

Portland cement, used as a solidification-, backfilland construction material, determines the chemistry of a low- and intermediate level radioactive waste repository for a very long period. A thermodynamic solubility model of the main constituents of hydrated portland cement has been developed by Berner [9] and has been used to predict the chemical evolution of cement structures degrading in groundwater. For the present study, the pore solution composition of sulphate resistant portland cement degrading in a marltype groundwater was taken from reference [9], the cement degradation being in an intermediate stage. The relevant parameters of the water description are given in Table 1. As the base case it was assumed that the aqueous $\mathrm{Ni}$ species are in equilibrium with solid NiO (Bunsenite). The speciation calculation of this base case results in a total $\mathrm{Ni}$ concentration in solution
Table 2. Results of speciation calculations for $\mathrm{Ni}$ in selected "water types" (base case without organics)

\begin{tabular}{|c|c|c|}
\hline Parameter & Cement pore water & Marl groundwater \\
\hline Aqueous speciation & $\begin{array}{l}\mathrm{Ni}(\mathrm{OH})_{3}^{-}(91.2 \%) \\
\mathrm{Ni}(\mathrm{OH})_{4}^{2-}(8.7 \%)\end{array}$ & $\begin{array}{lr}\mathrm{NiCO}_{3(\sim)} & (88.6 \%) \\
\mathrm{Ni}\left(\mathrm{CO}_{3}\right)_{2}^{2-} & (7.4 \%) \\
\mathrm{Ni}^{2+} & (2.3 \%) \\
\mathrm{NiSO}_{4(\mathrm{aq})} & (1.1 \%)\end{array}$ \\
\hline Solid & $\mathrm{NiO}$ (Bunsenite) & $\begin{array}{l}\text { "NiO" (hypothetical } \\
\text { solid, see text) }\end{array}$ \\
\hline Ni solubility & $1.6 \cdot 10^{-5} \mathrm{M}$ & $5.8 \cdot 10^{-8} \mathrm{M}$ \\
\hline
\end{tabular}

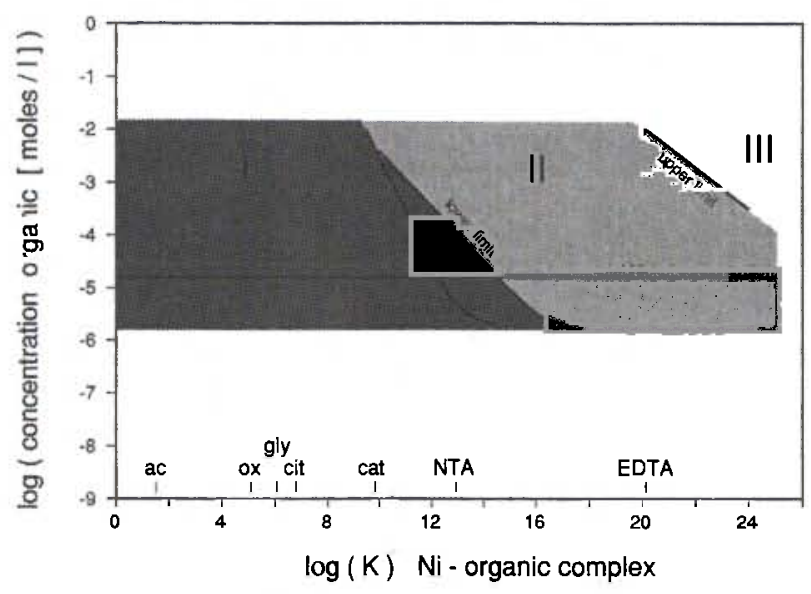

Fig. 6. Nickel solubility in pore water of a degrading sulphate resistant portland cement as a function of the concentration of an organic model ligand and the stability of the nickel-organic complex. The borderlines of regions I, II and II indicate a $10 \%$ increase of the nickel solubility with respect to the base case (no organic ligand).

of about $10^{-5} \mathrm{M}$ where the species are $\mathrm{Ni}$-hydroxo complexes (Table 2). Choosing $\mathrm{Ni}(\mathrm{OH})_{2}$ as the solubility limiting solid would not change the overall picture, except that the total Ni concentration would be increased by about $30 \%$. All the other solids given in reference [7] are totally soluble in the high $\mathrm{pH}$ cement pore water studied here, with the exception of a pyroxene-type silicate $\left(\mathrm{NiSiO}_{3}\right)$ which gives a $\mathrm{Ni}$ solubility of about $10^{-12} \mathrm{M}$. But pyroxenes precipitate at high temperatuers only and therefore $\mathrm{NiSiO}_{3}$ will not be in thermodynamic equilibrium with a solution at room temperature.

Having established the base case, the organic model ligand is "added" to the solution, i.e. the concentration of the ligand and the stability constant of its $\mathrm{Ni}$ - complex are varied in steps as described above and for each combination of the two parameters a new speciation calculation is done. As the main result, the total Ni concentration in solution is determined as a function of these two parameters. A significant influence of organics on the solubility of radionuclides is defined as a $10 \%$ increase of the total radionuclide concentration with respect to the base case, shown as $10 \%$-borderlines in the $\log$ concentration $-\log K_{\text {Niorg }}$ diagram (Fig. 6). Note that the Ni solubility as a func- 
tion of organic concentration and $\mathrm{Ni}-$ organic complex stability is represented by a rather steep surface and thus the results shown in Fig. 6 would not look much different if another level of significance is chosen. For example, showing results for a $20 \%$ increase would shift the borderlines in Fig. 6 by less than one $\log K$ unit to the right. Three different borderlines were determined considering the influence of competing cations on the $\mathrm{Ni}$-organic complex in different ways. In a first series of speciation calculations, the influence of competing cations is completely neglected, which results in the line labelled "none" in Fig. 6. In a second series, the influence of competing cations is included in the model, but it is assumed that the organic complexes with these cations are very weak, i.e. the "lower limit" functions of the stability data distributions are used (see $\log K$ ranges in Figs. 4 and 5 ). In a third series, the influence of competing cations is at its maximum, i.e. the "upper limit" functions of the $\log K$ data ranges are used. As can be seen in Fig. 6, the borderlines "none" and "lower limit" are quite close and converge with increasing organic concentrations. The borderline "none" is of course a completely hypothetical case, there is no common organic ligand known which forms complexes only with the radionuclide and none with the competing cations. But it clearly shows, if the complexes formed with the competing cations are weak, they have almost no influence on the speciation. Thus, the overall result shown in Fig. 6 is not changed if the "lower limit" function of the $\log K$ data range (e.g. Fig. 4) is changed to smaller values, as may be indicated by some data points lying below the current "lower limit" function in Fig. 4.

In essence, speciation calculations with the organic model ligand reveal three different possibilities as to the significance of organics, shown as regions I to III in Fig. 6. In region I where the stability constants of the organic complexes are low, no influence of organics on the speciation and solubility of the radionuclide is expected. If the stability of organic complexes is below $\log K=9$, the competing $\mathrm{Ni}$-hydroxo complexes are much stronger than the $\mathrm{Ni}$-organic complexes. As can be seen in Fig. 6, the borderline of region I strongly depends on the concentration of the organic ligand: If the concentration decreases the value of the stability constant increases, i.e. $\log K$ increases from about 9 at concentration $10^{-2}$ to about 15 at concentration $10^{-5} \mathrm{M}$. Inspecting the stability data of common $\mathrm{Ni}-$ organic complexes, entire classes of organic ligands can be said to have no influence on the solubility of $\mathrm{Ni}$ in cement pore water. Among these ligands are the carboxylic acids, represented by acetate (ac), oxalate (ox) and citrate (cit) in Fig. 6, simple amino acids like glycine (gly) or the catechol-type ligands (cat). In region II, the concentration - stability field limited by the borderlines "lower limit" and "upper limit", the stability of organic complexes with the competing cations determines the influence of the organic ligand on the speciation and solubility of the radionuclide. Here, only considering the two main parameters, concentration of the organic ligand and the stability of the radionuclide-organic complex, is insufficient to determine whether the organic ligand will have a significant influence or not. The stability constants of complexes with the competing cations also must be known. In the case of cement pore water, the main competing cation is $\mathrm{Ca}^{2+}$, thus at least the stability of the $\mathrm{Ca}$-organic complex must be known in addition to the stability of the $\mathrm{Ni}$ - organic complex. If we want to solve, for example, the case of the organic ligand NTA, we see from Fig. 6 that the stability constant of NiNTA lies in region I below a NTA concentration of about $10^{-4} \mathrm{M}$ and thus no influence of NTA below that concentration is expected. But above $10^{-4} \mathrm{M}$ NTA, in region II, the question cannot be answered using Fig. 6 alone, but we have to consider in addition the Ni-Ca $\log K$ data distribution (Fig. 4). As can be seen in Fig. 4, the stability of the CaNTA - complex is far from the lower limit of the $\log K$ range. On the other hand, even at high NTA concentrations $\left(10^{-2} \mathrm{M}\right)$ the stability constant of the NiNTA complex remains very close to the "lower limit" borderline of region II (Fig. 6). Thus, NTA is expected to have no significant influence on the solubility of $\mathrm{Ni}$ in cement pore water. As a second example, the influence of EDTA is determined. As can be seen in Fig. 6, the stability constant of NiEDTA entirely remains in region II up to an EDTA concentration of about $10^{-2} \mathrm{M}$, and therefore the answer depends on the stability constant of the CaEDTA complex. Inspecting Fig. 4 reveals that CaEDTA is rather close to the upper limit of the $\log K$ distribution but not exactly at the upper limit. Thus, comparing the data ranges in Figs. 4 and 6, as a first approximation EDTA is expected to have an influence on the solubility of $\mathrm{Ni}$ in cement pore water if the EDTA concentration in solution exceeds at least $10^{-3} \mathrm{M}$. For a more precise result ternary complexes which may form in the $\mathrm{Me}-$ EDTA- $\mathrm{OH}^{-}$system should be included into the speciation calculations. In region III where the stability constants of the organic complexes are high, strong influence of organics on the speciation and solubility of the radionuclide is expected. Here, the competing cations have no influence on the result, the radionuclide-organic complex is the only significant stability parameter. As can be seen in Fig. 6, this region is very small for cement pore water and only the strongest known EDTA - type ligands $(\log K \simeq 22$, Fig. 4) at concentrations above $10^{-3} \mathrm{M}$ reach this field.

\section{Marl groundwater}

As an example of the farfield water chemistry of a radioactive waste repository in sedimentary host rock, a marl - type groundwater was selected for the present study. A standard marl groundwater has been defined by Baeyens and Bradbury [10] using analytical data 
and geochemical reasoning. The relevant parameters of the water description are given in Table 1. Trying to establish a base case where the aqueous $\mathrm{Ni}$ species are in thermodynamic equilibrium with a $\mathrm{Ni}$ solid, however, caused problems. Using the thermodynamic data of $\mathrm{Ni}$ solids given in reference [7] to define a solubility limiting solid, no reasonable $\mathrm{Ni}$ concentration in solution resulted from the speciation calculations: The pyroxene-type silicate $\mathrm{NiSiO}_{3}$ yields a total Ni concentration in solution of about $10^{-13} \mathrm{M}$, but as discussed above it will not be in thermodynamic equilibrium with a solution at room temperature. Taking $\mathrm{NiO}$ (Bunsenite) as solubility limiting solid results in a total $\mathrm{Ni}$ concentration of $0.02 \mathrm{M}$, all other solids given in Reference [7] are totally soluble in the standard marl groundwater. Inspection of a large number of analytical data of Swiss groundwaters shows that the measured Ni concentrations never exceed $10^{-5} \mathrm{M}$. On the other hand, 143 water analyses out of 381 analyses yield Ni concentrations above the detection limit of about $10^{-8} \mathrm{M}$ with an average $\mathrm{Ni}$ concentration of about $10^{-7} \mathrm{M}$. These data suggest that if the $\mathrm{Ni}$ concentration in the standard marl groundwater is controlled by any solid at all, it cannot be one of the pure Ni solids given in Reference [7], but the aqueous $\mathrm{Ni}$ species may be in equilibrium with a solid solution containing $\mathrm{Ni}$ as minor component. Unfortunately no thermodynamic data about such solid solutions are available at present. Thus, in order to circumvent this problem the hypothetical pure $\mathrm{Ni}$ solid "NiO" was defined by the reaction:

$$
\mathrm{Ni}^{2+}+\mathrm{H}_{2} \mathrm{O} \rightleftharpoons \text { "NiO" }{ }_{\text {solid }}+2 \cdot \mathrm{H}^{*}
$$

and the stability constant of equilibrium (3) was chosen in such a way that the Ni concentration in the standard marl groundwater is close to $10^{-7} \mathrm{M}$. Using a stability constant of $\log K=-7$ for reaction (3), the speciation calculation of this base case results in a total Ni concentration in solution of $6 \cdot 10^{-8} \mathrm{M}$ where the Ni speciation is dominated by carbonato complexes (Table 2).

Having established the base case, the same procedure is followed as described for the cement pore water, i.e. the organic model ligand is "added" to the solution and speciation calculations are done varying its main parameters. The results for a $10 \%$ increase of the Ni solubility are shown in Fig. 7. The picture looks similar as the one shown in Fig. 6 but all borderlines are shifted to the left, that is towards lower stability constants, and the borderlines "none" and "lower limit" cannot be distinguished. The latter observation means that weak organic complexes with competing cations, i.e. complexes at the "lower limit" of the stability data distributions (Figs. 4 and 5), have no influence on the Ni solubility in the marl groundwater. As in the case of the cement pore water, the speciation calculations reveal three different regions I, II and II regarding the significance of organics (Fig. 7). In region $\mathrm{I}$ the $\mathrm{Ni}$-carbonato complexes are much stronger than the $\mathrm{Ni}$-organic complexes and no influ-

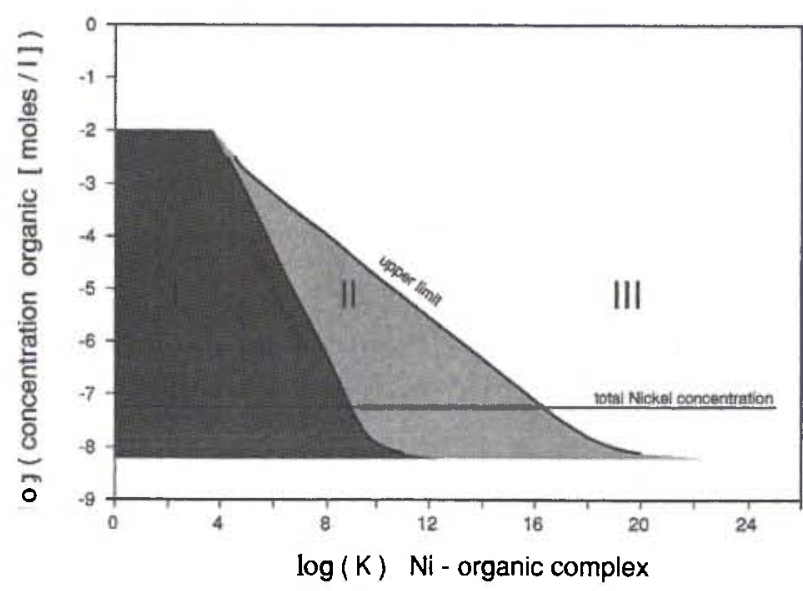

Fig. 7. Nickel solubility in a marl-type groundwater as a function of the concentration of an organic model ligand and the stability of the nickel-organic complex. The borderlines of regions I, II and II indicate a $10 \%$ increase of the nickel solubility with respect to the base case (no organic ligand).

ence of organics on the solubility of $\mathrm{Ni}$ is expected. In region II the influence of organics depend on the stability of organic complexes with the competing cations, mainly $\mathrm{Ca}$ and $\mathrm{Mg}$, and to a lesser extend $\mathrm{Sr}$. The weak $\mathrm{Na}$ - organic complexes have no significant influence on the speciation, despite of the high $\mathrm{Na}$ concentration. Region III, where strong influence of organics on the solubility of $\mathrm{Ni}$ is expected, is the largest of the three regions. As is shown in Fig. 7, this region extends to rather low stability constants at high concentrations of the organic ligand: $\log K \simeq 6$ at $10^{-3} \mathrm{M}$. Fig. 7 can be used to determine the influence of specific organic ligands on $\mathrm{Ni}$ in marl groundwater as discussed above for the case of cement pore water. For example, in contrast to cement pore water, EDTA is expected to show a strong influence on the solubility of $\mathrm{Ni}$ in marl groundwater even at very low concentrations, because NiEDTA lies entirely in region III.

\section{Conclusions}

The example results for two different water compositions show that the "backdoor approach" is a powerful method to estimate the influence of organics on the speciation and solubility of radionuclides: If the stabilities of the organic complexes with the radionuclide and the competing cations are known, the influence of entire classes of organic ligands can be determined by simply inspecting the relevant concentration-stability diagrams. If the stabilities of the organic complexes are unknown, e.g. in the case of natural organics, the important parameters are revealed. Depending on the water composition and on the selected radionuclide, it may turn out that only considering the two main parameters, concentration of the organic ligand and the stability of radionuclide - organic complexes, is insufficient to solve the problem. In this case, the "backdoor approach" shows which stability constants of complexes with competing 
cations also must be determined. Thus, the "backdoor approach" can be used to define the minimum data requirements needed to describe the influence of organics on radionuclide solubility.

Having show its feasibility, the new method will be applied to other, more relevant radioelements such as the actinides. The experience gained by studying the $\mathrm{Ni}$ system, which is one of the best known systems with respect to measured thermodynamic data, will help to establish parameter reducing correlations of stability constants for actinides where less experimental data are available.

\section{Acknowledgments}

I would like to thank Dr. U. Berner, Dr. J. Hadermann and Dr. R. Klos, as well as an anonymous reviewer, for their critical reviews of the manuscript and valuable comments. This work has been partially supported by the National Cooperative for the Storage of Radioactive Waste, Nagra.

\section{References}

1. Sargent, F. P., McKinley, I. G.: Geochemical and Chemical Data and Modeling for the Safety Assessment of Geological Disposal of High-Level Nuclear Waste, in: Safety Assessment of Radioactive Waste Repositories, Proceedings of the Paris Symposium 1989, OECD, Paris 1990, p. 543.

2. Read, D. (ed.): CHEMVAL PROJECT Report on Stage 2: Application of speciation models to laboratory and field data sets, CEC Report No. EUR 13124EN, Luxembourg 1990.

3. a. Martell, A. E., Smith, R. M.: Critical Stability Constants, Vol. 1, Amino Acids, Plenum Press, New York and London 1974

3. b. Smith, R. M., Martell, A. E.: Critical Stability Constants, Vol. 2, Amines, Plenum Press, New York and London 1975.
3. c. Martell, A. E., Smith, R. M.: Critical Stability Constants, Vol. 3, Other Organic Ligands, Plenum Press, New York and London 1977.

3. d. Martell, A. E., Smith, R. M.: Critical Stability Constants, Vol. 5, First Supplement, Plenum Press, New York and London 1982

3. e. Smith, R. M., Martell, A. E.: Critical Stability Constants, Vol. 6, Second Supplement, Plenum Press, New York and London 1989.

4. Chapman, N. B., Shorter, J.: Correlation Analysis in Chemistry: Recent Advances, Plenum Press, New York and London 1978.

5. Langmuir, D.: Techniques of Estimating Thermodynamic Properties for Some Aqueous Complexes of Geochemical Interest, in: Chemical Modeling in Aqueous Systems (E. A. Jenne, ed.), ACS Symposium Series 93, American Chemical Society, Washington 1979 , p. 353

6. Brown, P. L., Sylva, R. N.: Unified Theory of Metal Ion Complex Formation Constants, J. Chem. Research (S): $4-$ 5; (M): 0110-0181 (1987) and Report No. AAEC/E656, Australian Atomic Energy Commission 1987.

7. Baeyens, B., McKinley, I. G.: A PHREEQE Database for $\mathrm{Pd}$, Ni and Se, PSI-Report No. 34, Paul Scherrer Institute, CH-5232 Villigen PSI, 1989 and Nagra, Technical Report 89-28, Baden, Switzerland 1989.

8. Westall, J. C., Zachary, J. L., Morel, F. M. M.: MINEQL A Computer Program for the Calculation of Chemical Equilib rium Composition of Aqueous Systems, MIT Technical Note No. 18, Cambridge, Massachusetts, 1976.

9. Berner, U.: A Thermodynamic Description of the Evolution of Pore Water Chemistry and Uranium Speciation during the Degradation of Cement, PSI-Report No. 62, Paul Scherrer Institute, CH-5232 Villigen PSI, 1990 and Nagra, Technical Report 90-12, Baden, Switzerland 1990.

10. Baeyens, B., Bradbury, M. H.: A Physico-Chemical Characterisation Technique for Determining the Pore-Water Chemistry in Argillaceous Rocks, PSI-Report No. 103, Paul Scherrer Institute, $\mathrm{CH}-5232$ Villigen PSI, 1991 and Nagra, Technical Report 90-40, Baden, Switzerland 1991. 